Article

\title{
Evolution of the Structure of the Urban Land-Price System in China Based on the Rank-Size Law
}

\author{
Xiaoyu Liu ${ }^{1,2}$ and Liangjie Xin ${ }^{1, *}$ \\ 1 Key Laboratory of Land Surface Pattern and Simulation, Institute of Geographic Sciences and Natural \\ Resources Research, Chinese Academy of Sciences, Beijing 100101, China; liuxiaoyu8529@igsnrr.ac.cn \\ 2 College of Resources and Environment, University of Chinese Academy of Sciences, Beijing 100049, China \\ * Correspondence: xinlj@igsnrr.ac.cn
}

check for updates

Citation: Liu, X.; Xin, L. Evolution of the Structure of the Urban Land-Price System in China Based on the

Rank-Size Law. Land 2022, 11, 284.

https://doi.org/10.3390/

land11020284

Academic Editors: Piyush Tiwari and Hossein Azadi

Received: 19 January 2022

Accepted: 11 February 2022

Published: 13 February 2022

Publisher's Note: MDPI stays neutral with regard to jurisdictional claims in published maps and institutional affiliations.

Copyright: (C) 2022 by the authors. Licensee MDPI, Basel, Switzerland. This article is an open access article distributed under the terms and conditions of the Creative Commons Attribution (CC BY) license (https:/ / creativecommons.org/licenses/by/ $4.0 /)$.

\begin{abstract}
China's cities have experienced rapid and uneven development in recent decades, which influenced urban land prices crucially. Understanding the distribution of the urban land-price system and its evolution would help to provide an in-depth understanding of the development of China's urban system. Therefore, we combined rank-size law and fractal theory to analyze the patterns and variations of the rank-size distributions of China's urban land-price system based on land transfer data for 2007-2019. We concluded the following: (1) the rank-size law explains the distribution of the urban land-price system in China-the system was balanced and showed an equilibriumdisequilibrium development; (2) the actual land prices were higher than the theoretical land prices in southeastern China, especially in urban agglomerations, while they were lower in northwestern China; (3) the number of cities located in China's urban development system was decreasing, and the unevenness of urban land-price system was increasing; and (4) the imbalance of land-price rank-size distributions was higher in the Beijing-Tianjin-Hebei and Guangdong-Hongkong-Macau Greater Bay Area urban agglomerations, while they were more balanced in the Chengdu-Chongqing and Central Plains urban agglomerations. We suggest that the development of small cities in China has a large upside, which should be noticed.
\end{abstract}

Keywords: land transfer; land price; rank-size law; fractal theory; China; urban agglomeration

\section{Introduction}

Land price is a comprehensive reflection of a city's economic strength, population, industrial agglomeration, and other aspects of development [1-3]. Numerical changes and characteristics of spatial patterns and their factors can effectively reflect the development status of a city and the association between cities. China's economic center of gravity has shifted eastward, and the pattern of uneven regional development has rapidly emerged since the 1970s when China began to implement an unbalanced development strategy, which led to the rapid development of the eastern part of China in a short time [4]. In this context, a combination of two factors has led to widening differences in land prices between China's cities. First, the divergence of land demand guided by different development needs leads to differences in land prices between cities, resulting in the land price showing a trend of growth, which is aligned with growth of the economy [5]. Second, developed cities are more conducive for productive activities than backward cities, thus attracting the migration of capital, population, and industry, which increase the demand for land, causing differences in the rate of land price changes compared to other cities [6].

Land prices in China's cities are rising rapidly at varying rates based on their regions and are related to national economic development and urbanization. In addition, land prices are connected to national livelihood and social stability, which form the core of urban land policy formulation in China. Currently, studies on land prices in China have focused on spatial and temporal variations [7-10] and the analysis of their driving factors [11-13]. Among them, studies on spatial and temporal variation of urban land prices 
usually focus on land price changes within a city or a region, and polarization [14,15], agglomeration $[16,17]$, and spatial analysis $[18,19]$ are the common methods used in such studies. Studies on the driving factors of urban land price change focus on the role of economic, social, and locational factors on land prices, and commonly used methods include geographically weighted regressions and geodetector $[7,20,21]$. The above studies analyze the changes and differences in land prices in regions with small areas based on a microscopic perspective, which is difficult for reflecting the relationship between urban land prices but is rarely concerned about the operational status and development of China's urban land-price system based on a macroscopic perspective [22]. Therefore, the purpose of this study is to clarify the distribution pattern of the current urban land-price system in China, and to judge whether the distribution is balanced and how this distribution develops and changes.

Current methods for analyzing the state of urban systems and their attributes include the social network model [23], chain network model [24], and rank-size law [25]. Among them, the rank-size law can portray the distribution relationship and degree of equilibrium between elements for different ranks in a system compared with other methods, which are otherwise difficult to obtain intuitively. Thus, the rank-size law is widely applied to system-based studies, and it has been gradually extended to other fields of study such as airport systems [26], port systems [27-29], foreign trade [30], tourism flow [31,32], and resource flow [33,34]. However, studies on the application of the rank-size law to land prices, especially in terms of long time series and large scales are rare. The rank-size law was first applied to describe the relationship between population size and rank of cities $[35,36]$, and later it was used to reflect the distribution of city size in the urban system [37-39]. Theoretically, land price and population size of a city reflect the comprehensive development level of the city [40]. Urban land price and population size show a strong positive correlation that population size transmits to land price by affecting the demand for land, and land price affects population size by affecting the living cost of residents [20,41]. Generally, the larger the population, the higher the land price of the city. Therefore, the distribution of urban land prices should be in line with the rank-size rule. Understanding the rank-size distribution of the urban land-price system at the national scale will provide an understanding of the rank-size relationships among cities and the equilibrium of China's urban land-price system. In addition, the rank-size distribution of the urban land-price system reflects the demographic, economic, and social development of cities and the degree of equilibrium of the urban system. Urban agglomerations can be regarded as a system formed by the artificial division of China's urban land-price system because it is a collection of several cities in a region. Therefore, it is beneficial to identify whether the distribution of land prices within urban agglomerations conforms to the rank-size law and reflects the differences among urban agglomerations to further analyze and understand China's urban land-price system from a relatively microscopic perspective.

The Ministry of Land and Resources successively issued two policies in 2006 for trial implementation, namely, "Norms for Bidding, Auctioning, and Listing of State-owned Land Use Rights" and "Norms for Agreed Grant of State-owned Land Use Rights", thereby marking the beginning of a market-oriented and standardized operation of the transfer of state-owned land-use rights in China. To this end, to reveal the distribution of the urban land-price system, its degree of equilibrium, the gap between the actual and theoretical valuations, and other characteristics, and to reflect the equilibrium of the development of the urban system in China. this study uses state-owned land transfer data published by the China Land Market Network to quantitatively measure the distribution pattern of land prices and their variations in China's urban system and major urban agglomerations during 2007-2019, when the land market was relatively high, using the prefecture-level administrative district as the unit and by combining rank-size law and fractal theory. The results of this study are expected to provide a scientific basis for the formulation of landprice macro-regulation policies and the promotion of coordinated regional development. 


\section{Materials and Methods}

\subsection{Calculation of Land Price}

The average land prices of eight major land-use types that were transferred through agreement, tender, auction, or listing during 2007-2019 were used as the urban land price based on Equation (1) as follows:

$$
o L P_{i, j}=\frac{\sum_{k=1}^{n} l p_{i, j, k}}{\sum_{k=1}^{n} A_{i, j, k}}
$$

where $o L P_{i, j}$ represents the average land price for city $j$ in year $i, n$ is the total number of land-use types transferred in city $j$ in year $i, l p_{i, j, k}$ is the land price for land-use type $k$ in city $j$ in year $i$, and $A_{i, j, k}$ represents the total area transferred for land-use type $k$ in city $j$ in year $i$.

\subsection{Land Price Revision}

Considering that the land price in the original data is the price in the respective years, a direct comparison cannot be made for different years. Therefore, the consumer price index (CPI) values for 2008-2019 were used to revise the land price to a constant in 2007 to eliminate the effects of price changes (Equation (2)) [42-44].

$$
L P_{i}=o L P_{i} \times \prod_{t=1}^{i} \frac{100}{C P I_{t}},(i \in[2,13])
$$

where $L P_{i}$ represents the revised land price in year $i, o L P_{i}$ is the original land price in year $i$, and $C P I_{t}$ is the consumer price index in year $t$.

\subsection{Spatial Autocorrelation Analysis}

To describe the spatial distribution of urban land prices in China and to measure the correlation between land prices in a city and its neighboring cities, Global Moran's I and Local Moran's I are used to measure the spatial agglomeration of urban land prices in China and the specific locations where the spatial agglomeration occurs (Equations (3) and (4)) $[18,19]$.

$$
\begin{gathered}
\text { Global Moran's } I=\frac{n \sum_{i=1}^{n} \sum_{j=1}^{n} W_{i j}\left(x_{i}-\bar{x}\right)\left(x_{j}-\bar{x}\right)}{\left(\sum_{i=1}^{n} \sum_{j=1}^{n} W_{i j}\right) \sum_{i=1}^{n}\left(x_{i}-\bar{x}\right)^{2}},(i \neq j) \\
\text { Local Moran's } I=\frac{n\left(x_{i}-\bar{x}\right) \sum_{i=1}^{n} W_{i j}\left(x_{j}-\bar{x}\right)}{\sum_{i=1}^{n}\left(x_{i}-\bar{x}\right)^{2}},(i \neq j)
\end{gathered}
$$

where $x_{i}$ and $x_{j}$ represent the land prices of city $i$ and city $j, n$ represents the number of cities, $m$ represents the number of cities geographically adjacent to the city $i, \bar{x}$ represents the average land price, and $W_{i j}$ represents the spatial arrangement of cities. The value range of Global Moran's $I$ is from -1 to 1 , the significance of which can be tested by the $Z$ (Equation (5)).

$$
Z=\frac{I-E(I)}{\sqrt{\operatorname{VAR}(I)}}
$$

where the $E(I)$ is the mean value of Global Moran's $I$, and $V A R(I)$ is the variance of Global Moran's I. 


\subsection{Rank-Size Law}

The rank-size law was used to analyze the relationship between land price and its rank in China's urban system. Equation (6) was developed using land prices and their ranks based on Lotka's formula [25]:

$$
L P_{i, j}=T L P_{i, 1} R_{i, j}^{-q_{i}},(q>0)
$$

where $L P_{i, j}$ represents the land price for city $j$ in year $i, R_{i, j}$ represents the land-price rank for city $j$ in year $i$, and the lower $R$ is, the higher land price and its rank, TLP $P_{i, 1}$ represents the urban land-price that theoretically ranks first in year $i, q_{i}$ represents the Zipf dimension, $q>1$ means that the cities' land prices are distributed intensively in urban systems with the characteristic of a stronger monopoly in the city that is ranked first and the occurrence of prominent land prices in the high-ranking cities, $q<1$ means that the cities' land prices are distributed dispersedly in the urban system with the characteristic of an even distribution of land prices across cities, and $q=1$ means that the land price in each city is close to the Zipf ideal, and the number of cities with different land prices is proportionally balanced.

Moreover, the ratios of theoretical land price to actual land price for various cities were calculated to demonstrate the differences among them (Equation (7)).

$$
r_{i, j}=\frac{T L P_{i, 1} R_{i, j}^{-q_{i}}}{L P_{i, j}}
$$

where $r_{i, j}$ represents the ratio of theoretical land price to actual land price for city $j$ in year $i, r>1$ indicates that the theoretical land price is higher than the actual land price, $r<1$ indicates that the theoretical land price is lower than the actual land price, and $r=1$ indicates that the theoretical land price is equal to the actual land price.

\subsection{Fractal Theory}

To further explore whether the distribution of the urban land-price system has fractal characteristics that are similar to the distributions of city sizes [45], the double logarithmic distribution of land prices and their ranks were obtained by the logarithmic variation of Equation (6) (Equation (8)). Accordingly, the number and range of non-scale areas can be obtained using the linear fit (if the logarithmic scatterplot has segmental characteristics, the segmented linear fit will be applied) of the logarithmic scatterplot of land prices and their ranks.

$$
\begin{gathered}
\ln L P_{i}=\ln L P_{1}-q \ln R_{i},(q>0) \\
D=\frac{R^{2}}{q}
\end{gathered}
$$

The sub-dimensional value $D$ in the Pareto formula [46] was introduced to reflect the degree of equilibrium of the urban land-price system, which can be calculated using the ratio of $R^{2}$ of the rank-size expression to $q$ (Equation (9)). The larger the $D$, the closer the urban-land prices are in the system and the more balanced the system is. The lower the $D$ is, the greater are the differences between the land prices of high-ranking and low-ranking cities in the system and the system is more unbalanced.

\subsection{Data Sources and Processing}

Land transfer data were obtained from the information on the primary land market transactions during 2007-2019 that was released by the China Land Market Network (http: / / www.landchina.com, accessed on 19 January 2022), which includes a total of 2,290,619 transfer records of land parcels. Data cover eight major land-use types according to the classification of current land use (GB/T 21010-2017), including residential, commercial, industrial and mining storage, public management service, transportation, water conservancy facilities, specially designated land, and other lands. Although the proportion 
of land area that was transferred based on agreement decreases during the study period, it continues to contribute a significant proportion of transactions and the transfer prices associated with such transactions are similar to those of the prices in the tenders, auctions, and listings of earlier years, which is due to the implementation of the market-oriented land transfer policy. To ensure the completeness of data and avoid bias caused by the low quantity of data in the actual versus calculated prices in the tenders, auctions, and listings, which are market-based transfer methods, the records on land transfer through the four types were considered. Data were preprocessed by eliminating records with missing key information and those records with land prices in the top and bottom $5 \%$ of each city each year, and retaining records of lands that were transferred by agreement, tender, auction, and listing. A total of 1,430,275 land transfer records covering 328 prefecture-level administrative units in China were obtained, including 290 prefecture-level cities, 29 autonomous prefectures, three league cities, and six regions. The administrative district criteria were derived from the 2017 district codes and urban-rural division codes for statistical purposes published by the National Bureau of Statistics, China [47].

Moreover, data were further processed to obtain the average land price of all land-use types in each city during 2007-2019. The land prices of all cities were ranked from the highest to the lowest for each year to obtain the land-price rank of each city based on the average land prices of cities.

We selected eight national-level urban agglomerations that contained a relatively large number of cities to analyze the distribution and equilibrium of land prices and compare the differences among them. The urban agglomerations of the Middle Reaches of the Yangtze River (MRY), Chengdu-Chongqing (CC), the Yangtze River Delta (YRD), Central Plains $(\mathrm{CP})$, Beibu Gulf (BG), Beijing-Tianjin-Hebei (BTH), Harbin-Changchun (HC), and the Guangdong-Hongkong-Macau Greater Bay Area (GHM) were included. The list of cities and spatial distribution of urban agglomerations are shown in Table 1 and Figure 1.

Table 1. List of cities included in China's major urban agglomerations.

\begin{tabular}{|c|c|c|}
\hline Urban Agglomeration & Number of Cities & List of Cities in Urban Agglomeration \\
\hline $\mathrm{CP}$ & 29 & $\begin{array}{l}\text { Zhengzhou, Luoyang, Kaifeng, Nanyang, Anyang, Shangqiu, Xinjiang, } \\
\text { Pingdingshan, Xuchang, Jiaozuo, Zhoukou, Xinyang, Zhumadian, Hebi, } \\
\text { Puyang, Luohe, Sanmenxia, Changzhi, Jincheng, Yuncheng, Xingtai, Handan, } \\
\text { Liaocheng, Heze, Suzhou, Huaibei, Bengbu, Fuyang, and Bozhou }\end{array}$ \\
\hline MRY & 28 & $\begin{array}{c}\text { Wuhan, Huangshi, Ezhou, Huanggang, Xiaogan, Xianning, Xiangyang, } \\
\text { Yichang, Jinzhou, Jinmen, Changsha, Zhuzhou, Xiangtan, Yueyang, Yiyang, } \\
\text { Changde, Hengyang, Loudi, Nanchang, Jiujiang, Jingdezhen, Yingtan, Xinyu, } \\
\text { Yichun, Pingxiang, Shangrao, Fuzhou, and Ji'an }\end{array}$ \\
\hline YRD & 27 & $\begin{array}{l}\text { Shanghai, Nanjing, Wuxi, Changzhou, Suzhou, Nantong, Yangzhou, } \\
\text { Zhenjiang, Yancheng, Taizhou (in Jiangsu), Hangzhou, Ningbo, Wenzhou, } \\
\text { Huzhou, Jiaxing, Shaoxing, Jinhua, Zhoushan, Taizhou (in Zhejiang), Hefei, } \\
\text { Wuhu, Ma'anshan, Tongling, Anqing, Chuzhou, Chizhou, and Xuanchng }\end{array}$ \\
\hline $\mathrm{CC}$ & 16 & $\begin{array}{l}\text { Chengdu, Chongqing, Zigong, Luzhou, Deyang, Suijing, Neijiang, Leshan, } \\
\text { Nanchong, Meishan, Yibin, Guang'an, Ziyang, Mianyang, Dazhou, and Ya'an }\end{array}$ \\
\hline BTH & 11 & $\begin{array}{c}\text { Beijing, Tianjin, Shijiazhuang, Tangshan, Baoding, Qinhuangdao, Langfang, } \\
\text { Cangzhou, Chengde, Zhangjiakou, and Hengshui }\end{array}$ \\
\hline GHM & 11 & $\begin{array}{c}\text { Guangzhou, Shenzhen, Foshan, Dongguan, Zhongshan, Zhuhai, Jiangmen, } \\
\text { Zhaoqing, Huizhou, Hongkang *, and Macau * }\end{array}$ \\
\hline $\mathrm{HC}$ & 11 & $\begin{array}{c}\text { Harbin, Daqing, Tsitsihar, Suihua, Mudanjiang, Changchun, Jilin, Siping, } \\
\text { Liaoyuan, Songyuan, and Yanbian }\end{array}$ \\
\hline BG & 10 & $\begin{array}{c}\text { Nanning, Beihai, Qinzhou, Fangchenggang, Yulin, Chongzuo, Zhanjiang, } \\
\text { Maoming, Yangjiang, and Haikou }\end{array}$ \\
\hline
\end{tabular}

${ }^{*}$ Limited by data acquisition, Hong Kong and Macau were not included for GHM calculations. 


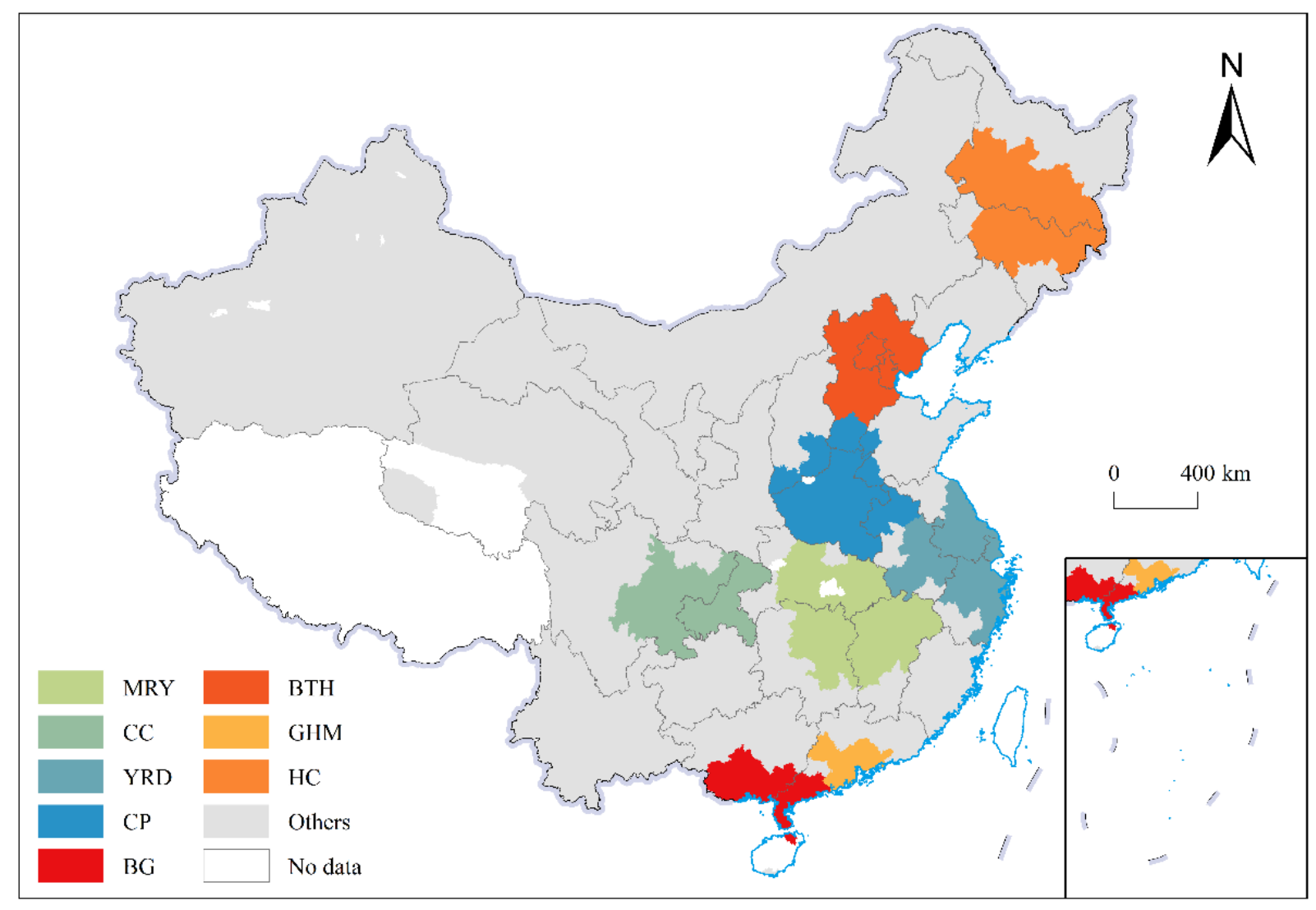

Figure 1. Spatial distribution of major urban agglomerations in China.

In addition, gross domestic product (GDP) and permanent population data were obtained from the statistical yearbooks of China's provinces. The GDP data were revised to constant prices of 2007 using the CPI during 2008-2019.

\section{Results}

\subsection{Temporal Evolution and Spatial Pattern of Urban Land Prices}

Temporally, the average urban land price in China shows a significant upward trend (Figure 2a), increasing from 392.34 yuan $/ \mathrm{m}^{2}$ in 2007 to 1357.31 yuan $/ \mathrm{m}^{2}$ in 2019, with an average growth rate of 80.73 yuan $/\left(\mathrm{m}^{2} \cdot \mathrm{a}\right)$, a total increase of $245.95 \%$ and an average annual growth rate of $11.49 \%$. Spatially, in 2019 for example, urban land prices in China are spatially autocorrelated and exhibit a significant clustering distribution (Global Moran's $\mathrm{I}=0.15, \mathrm{Z}=4.63, p<0.001$ ). Further analysis of the location of clusters reveals that HighHigh clusters appear in the eastern part of China, concentrated in Tianjin, Zhejiang, and Guangdong. Low-Low clusters appear on a large scale in the northwestern part of China. In addition, the High-Low outlier is mainly found in northeastern China, with scattered distribution in central and northwestern China; the Low-High outlier is found in Hebei, Hainan, and the eastern coastal region of China (Figure 2b).

\subsection{Rank-Size Distribution Characteristics of the Urban Land-Price System in China}

Figure 3 demonstrates that the rank-size curve fits the land prices and their ranks in the urban system with an $R^{2}$ of 0.96 in 2019. Zipf and D of the rank-size curve were 0.67 and 1.45 , respectively, indicating that the urban land prices were distributed evenly and the distribution of the urban land-price system was balanced. Specifically, urban land prices in the 31-75 and 101-148 ranks of the urban land-price system were distributed above the rank-size curve, indicating that their actual land prices were higher than their theoretical land prices in the system. Urban land prices in the 180-328 ranks were distributed below 
the rank-size curve, reflecting that actual land prices were lower than the theoretical land prices.
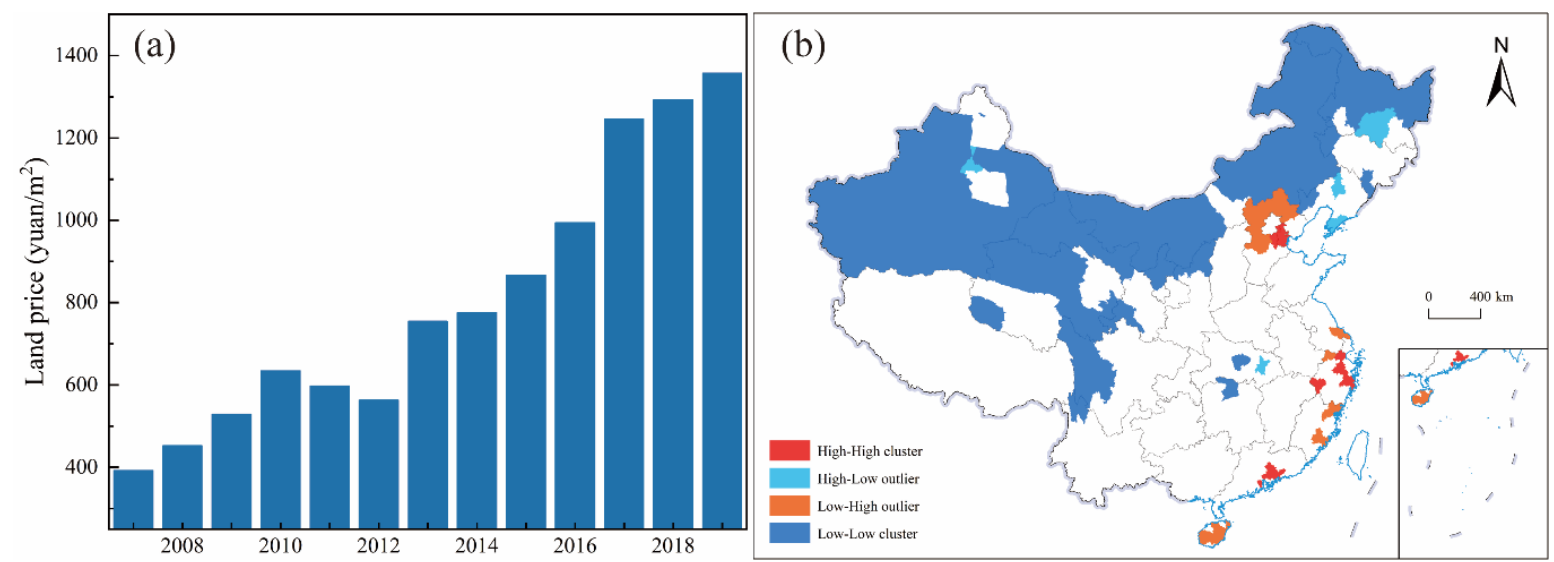

Figure 2. Temporal variation of average urban land prices (a) and spatial agglomerations of urban land prices (b) in China.
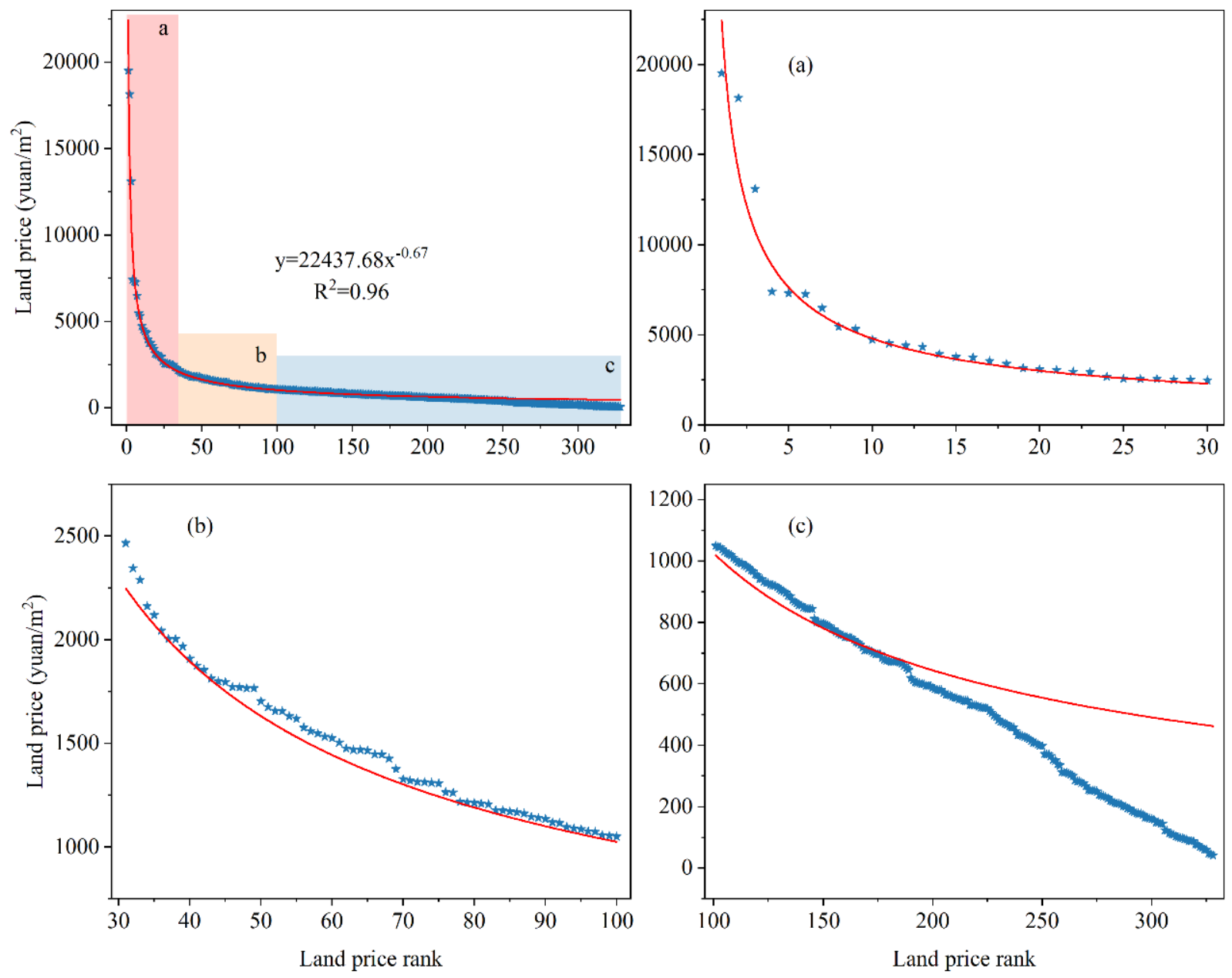

* City - Rank-size curve

Figure 3. Rank-size distribution of China's urban land-price system in 2019. Rank-size curves of the urban land-price system in China for ranks (a) 1 to 30, (b) 31 to 100, and (c) 101 to 328. 
The $r$ of cities in 2019 was calculated to further clarify the spatial pattern of the difference between the theoretical and actual land prices of China's cities (Figure 4). Results show spatial patterns of low and high prices in the southeast and northwest, respectively, wherein the low values were concentrated in the eastern region, especially in the urban agglomerations of $\mathrm{HC}, \mathrm{BTH}, \mathrm{CP}, \mathrm{CC}$, and YRD. On the other hand, high values were mainly clustered in the northwestern region, with some areas distributed in the central-eastern region. This spatial pattern reflects a strong coupling correlation in land prices among cities within the urban agglomeration.

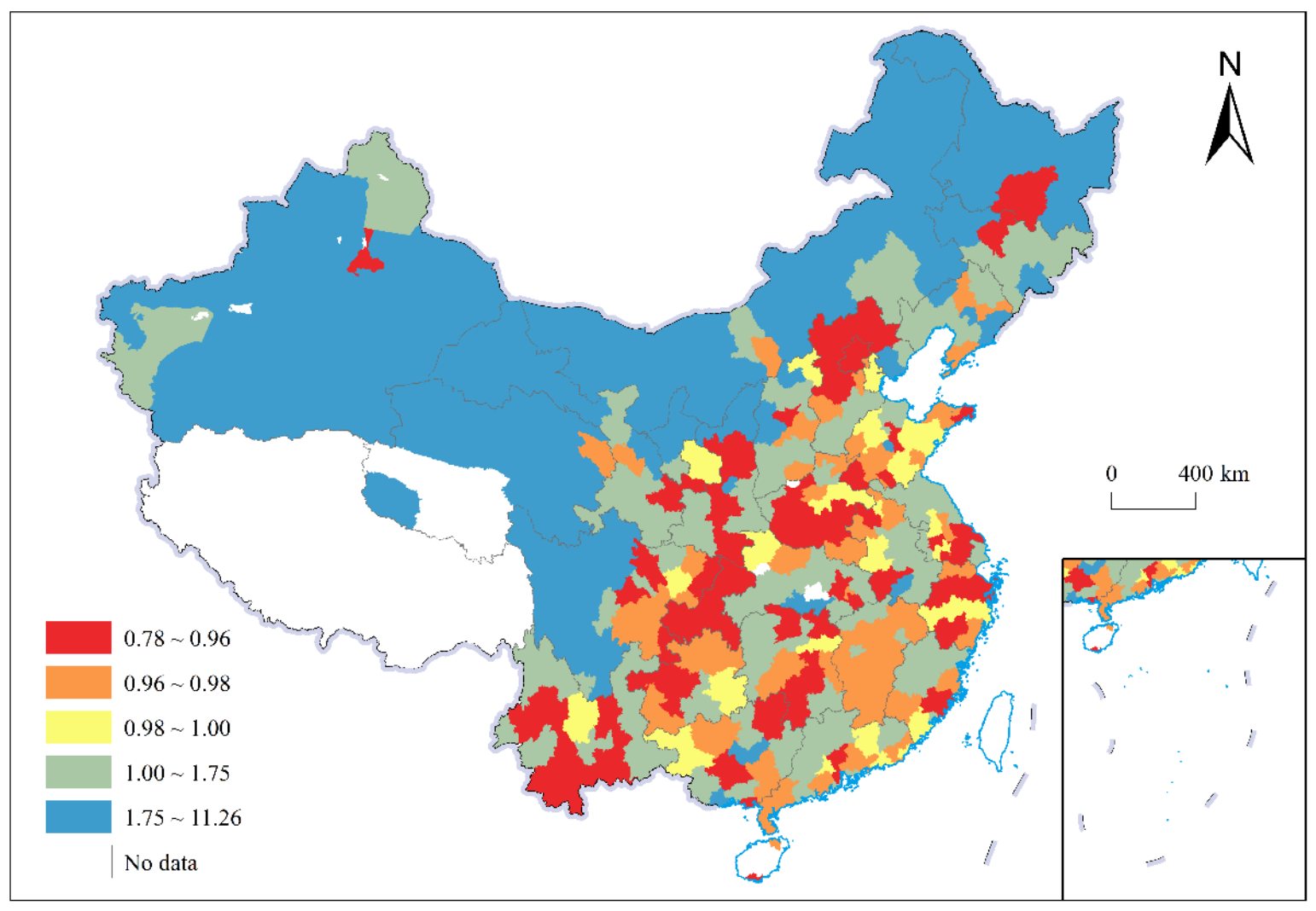

Figure 4. The ratio of theoretical to actual land prices of China's cities in 2019.

Temporally (Table 2), the $R^{2}$ was $>0.91$ during 2007-2019, indicating that the distribution and changes in China's urban land-price system could be explained by the parameters of the rank-size curve. Overall, the Zipf was $<0.8$ during the study period, which reflects that more cities were in low ranks and were less prominent among the high-ranking cities of the urban land-price system in China. Although Zipf and D fluctuated during 2007-2019, Zipf values showed a trend of decreasing and then increasing, while the D values showed a trend of increasing and then decreasing, which indicate that the equilibrium of rank-size distribution of China's urban land-price system first increased and gradually decreased after 2012. The monopoly of cities with higher land prices showed a trend of first weakening and then increasing. Additionally, the rank-size curves of land prices in 2007, 2013, and 2019 exhibit a shift to the right (Figure 5), and the theoretical land prices of the primary city during the study period showed a fluctuating increasing trend, rising from 3206.38 yuan $/ \mathrm{m}^{2}$ in 2007 to $22,437.68$ yuan $/ \mathrm{m}^{2}$ in 2019 , reflecting an improvement in the general level of urban-land prices in China. 
Table 2. Parameters of the rank-size distribution of the urban land-price system in China during 2007-2019.

\begin{tabular}{ccccc}
\hline Year & Rank-Size Function & Primary City & $\mathbf{R}^{\mathbf{2}}$ & $\mathbf{D}$ \\
\hline 2007 & $L P_{i}=3206.38 R_{i}^{-0.51}$ & Xiamen & 0.97 & 1.90 \\
2008 & $L P_{i}=3029.88 R_{i}^{-0.47}$ & Xiamen & 0.93 & 2.00 \\
2009 & $L P_{i}=6121.17 R_{i}^{-0.61}$ & Xiamen & 0.97 & 1.59 \\
2010 & $L P_{i}=4826.45 R_{i}^{-0.51}$ & Sanya & 0.96 & 1.88 \\
2011 & $L P_{i}=4021.62 R_{i}^{-0.46}$ & Wenzhou & 0.95 & 2.06 \\
2012 & $L P_{i}=3634.31 R_{i}^{-0.43}$ & Sanya & 0.91 & 2.11 \\
2013 & $L P_{i}=7035.58 R_{i}^{-0.52}$ & Beijing & 0.93 & 1.79 \\
2014 & $L P_{i}=9584.63 R_{i}^{-0.60}$ & Beijing & 0.96 & 1.60 \\
2015 & $L P_{i}=16,929.81 R_{i}^{-0.75}$ & Beijing & 0.97 & 1.31 \\
2016 & $L P_{i}=16,937.95 R_{i}^{-0.68}$ & Shenzhen & 0.93 & 1.37 \\
2017 & $L P_{i}=31,174.99 R_{i}^{-0.80}$ & Shenzhen & 0.98 & 1.23 \\
2018 & $L P_{i}=17,603.78 R_{i}^{-0.63}$ & Shenzhen & 0.97 & 1.52 \\
2019 & $L P_{i}=22,437.68 R_{i}^{-0.67}$ & Shenzhen & 0.96 & 1.45 \\
\hline
\end{tabular}

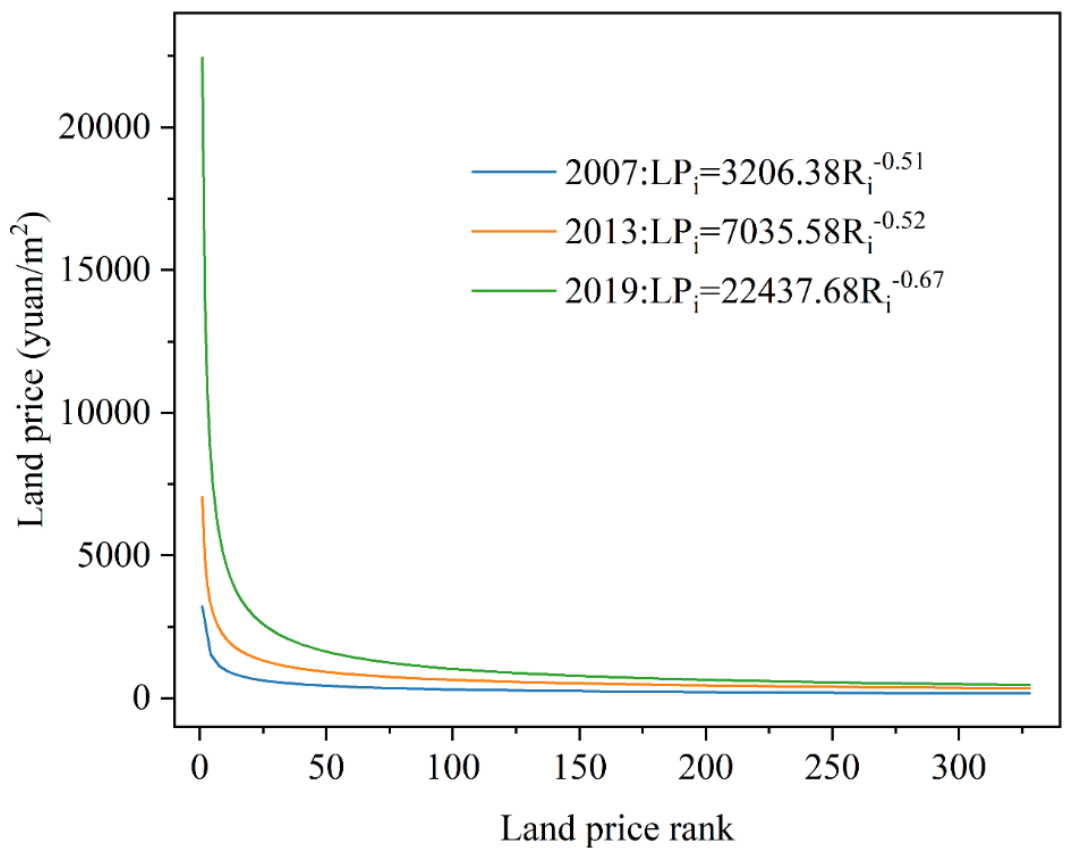

Figure 5. Land price rank-size curves of China's cities in 2007, 2013, and 2019.

The double-logarithmic relationship between land prices and their ranks of the urban system exhibited a significant turnaround; that is, they showed fractal characteristics during 2007-2019. Global error sum of squares at different points were further calculated and the minimum value was searched to determine the breakpoint of the double logarithmic relationship, and linear fits were performed before and after the breakpoint. After repeated tests, the best fit of the model as a whole was achieved when one turning point and two straight lines were used for the fit, showing that the double logarithmic relationship of land price rank-size conforms to the double fractal structure; that is, China's urban landprice system was divided into two subsystems-namely, non-scale areas I and II (Table 3). The cities in non-scale area I entered China's urban development system. These cities were closely interconnected in many aspects, interdependent and constrained, and their development can follow the pace of the overall national development. However, the cities in non-scale area II are not part of China's urban development system and they interact less. Therefore, it is difficult to compare the cities in non-scale area I with those in non-scale area II. Taking 2019 as an example (Figure 6a), the results of the double-log scatter plot 
and segmented linear fit of land prices and their ranks showed a significant turnaround, forming two non-scale areas with a turnaround point land-price rank of 242, corresponding to a land price of $482.19 \mathrm{yuan} / \mathrm{m}^{2}$. This indicates that 242 cities in non-scale area I entered China's urban development system in 2019, while 86 cities in non-scale area II did not enter the system.

Table 3. Piecewise linear fitting results of the double-logarithmic relationship between urban land prices and their ranks in China during 2007-2019.

\begin{tabular}{|c|c|c|c|c|c|c|}
\hline \multirow{2}{*}{ Year } & \multicolumn{2}{|l|}{ Non-Scale Area I } & \multicolumn{2}{|l|}{ Non-Scale Area II } & \multirow{2}{*}{$\begin{array}{c}\text { Land-Price } \\
\text { Rank of the } \\
\text { Turning Point }\end{array}$} & \multirow{2}{*}{$\begin{array}{l}\text { Land Price of the } \\
\text { Turning Point } \\
\left(y u a n / \mathrm{m}^{2}\right)\end{array}$} \\
\hline & Fitted Function & $\mathbf{R}^{2}$ & Fitted Function & $\mathbf{R}^{2}$ & & \\
\hline 2007 & $\ln L P_{i}=8.39-0.58 \ln R_{i}$ & 0.97 & $\ln L P_{i}=64.76-10.58 \ln R_{i}$ & 0.85 & 280.42 & 165.06 \\
\hline 2008 & $\ln L P_{i}=8.47-0.57 \ln R_{i}$ & 0.96 & $\ln L P_{i}=74.52-12.24 \ln R_{i}$ & 0.75 & 287.48 & 184.30 \\
\hline 2009 & $\ln L P_{i}=8.85-0.64 \ln R_{i}$ & 0.98 & $\ln L P_{i}=54.44-8.74 \ln R_{i}$ & 0.70 & 276.54 & 194.46 \\
\hline 2010 & $\ln L P_{i}=8.70-0.55 \ln R_{i}$ & 0.98 & $\ln L P_{i}=29.27-4.30 \ln R_{i}$ & 0.85 & 240.52 & 288.27 \\
\hline 2011 & $\ln L P_{i}=8.63-0.53 \ln R_{i}$ & 0.95 & $\ln L P_{i}=53.79-8.60 \ln R_{i}$ & 0.80 & 269.44 & 284.64 \\
\hline 2012 & $\ln L P_{i}=8.59-0.51 \ln R_{i}$ & 0.95 & $\ln L P_{i}=51.90-8.28 \ln R_{i}$ & 0.88 & 264.58 & 305.35 \\
\hline 2013 & $\ln L P_{i}=9.12-0.58 \ln R_{i}$ & 0.99 & $\ln L P_{i}=41.93-6.50 \ln R_{i}$ & 0.80 & 256.48 & 358.31 \\
\hline 2014 & $\ln L P_{i}=9.16-0.59 \ln R_{i}$ & 0.98 & $\ln L P_{i}=50.88-8.08 \ln R_{i}$ & 0.85 & 262.53 & 356.26 \\
\hline 2015 & $\ln L P_{i}=9.41-0.65 \ln R_{i}$ & 0.98 & $\ln L P_{i}=43.83-6.84 \ln R_{i}$ & 0.93 & 259.31 & 333.13 \\
\hline 2016 & $\ln L P_{i}=9.82-0.72 \ln R_{i}$ & 0.99 & $\ln L P_{i}=49.20-7.79 \ln R_{i}$ & 0.89 & 262.57 & 335.20 \\
\hline 2017 & $\ln L P_{i}=10.31-0.79 \ln R_{i}$ & 0.99 & $\ln L P_{i}=39.26-6.04 \ln R_{i}$ & 0.89 & 249.54 & 382.59 \\
\hline 2018 & $\ln L P_{i}=9.96-0.67 \ln R_{i}$ & 0.98 & $\ln L P_{i}=42.04-6.50 \ln R_{i}$ & 0.86 & 244.57 & 525.85 \\
\hline 2019 & $\ln L P_{i}=10.18-0.71 \ln R_{i}$ & 0.99 & $\ln L P_{i}=40.97-6.33 \ln R_{i}$ & 0.93 & 239.63 & 546.37 \\
\hline
\end{tabular}
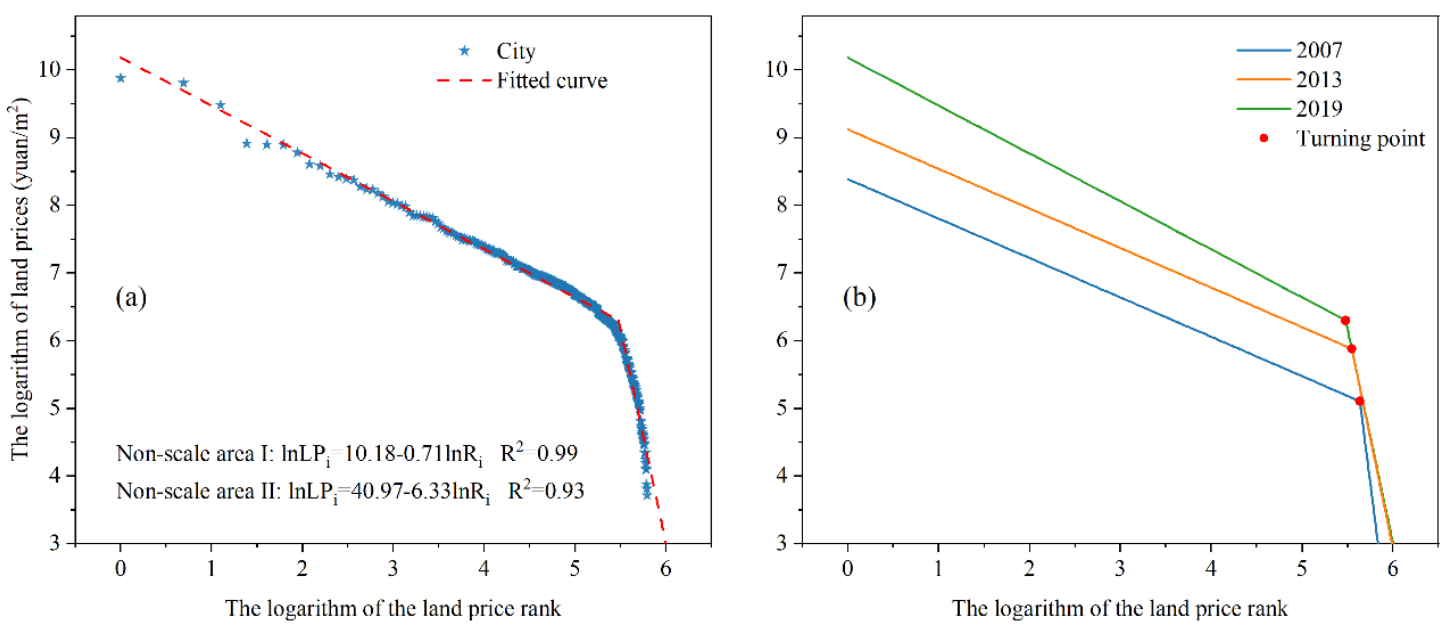

Figure 6. Results of the double-logarithmic piecewise linear fit of rank-size in China's urban-land prices (a) in 2019 and (b) in 2007, 2013, and 2019.

Based on Table 3 and Figure $6 \mathrm{~b}$, we concluded that the land-price rank of the turning point during 2007-2019 tends to decrease, moving forward from the 280th position in 2007 to the 239th position in 2019, which indicates that at least 41 cities gradually moved out of the urban development system in the development process. This phenomenon also shows that the range of non-scale area I keeps shrinking, and the unevenness of the land-price system gradually expanded as more cities moved from non-scale area I to non-scale area II during the development process. Moreover, as the fitted curve of non-scale area I became steeper and the fitted curve of non-scale area II became smoother, the difference between the slopes of non-scale area II and non-scale area I decreased, indicating that the difference in the degree of equilibrium of the urban land-price system within non-scale areas I and II decreased. 


\subsection{Rank-Size Characteristics of the Land-Price System in Urban Agglomerations}

The rank-size distribution patterns and equilibrium of the urban land-price system in eight major urban agglomerations in China showed that the rank-size law describes the distribution of the urban land-price system within the urban agglomerations (Table 4). Among the eight urban agglomerations, BTH had the highest Zipf (2.07) and the lowest $\mathrm{D}(0.48)$, indicating that its primary urban land price was the most dominant among them. The dominance of high-ranking cities in GHM was strong (Zipf $=1.27)$, indicating that the land prices of high-ranking and low-ranking cities were more disparate, and the overall equilibrium of land prices in the urban agglomerations was low. The degrees of equilibrium of the urban land-price systems of BG, HC, MYR, and YRD were in the middle level among the eight urban agglomerations, with decreasing Zipf and increasing D. CC and $\mathrm{CP}$ had the lowest Zipf and the largest $\mathrm{D}$, and their urban land-price systems were the most balanced, reflecting that the land prices of their high-ranking cities were not high among all urban agglomerations.

Table 4. Parameters of the rank-size curve for the urban land-price system of major urban agglomerations in China in 2019.

\begin{tabular}{ccccc}
\hline Urban Agglomerations & Rank-Size Function & Primary City & $\mathbf{R}^{\mathbf{2}}$ & $\mathbf{D}$ \\
\hline GHM & $L P_{i}=19,434.39 R_{i}^{-1.27}$ & Shenzhen & 0.99 & 0.78 \\
BTH & $L P_{i}=17,984.98 R_{i}^{-2.07}$ & Beijing & 0.99 & 0.48 \\
YRD & $L P_{i}=8638.68 R_{i}^{-0.58}$ & Shanghai & 0.89 & 1.54 \\
MRY & $L P_{i}=4454.43 R_{i}^{-0.66}$ & Wuhan & 0.97 & 1.47 \\
BG & $L P_{i}=3707.14 R_{i}^{-0.88}$ & Haikou & 0.96 & 1.09 \\
CC & $L P_{i}=2876.58 R_{i}^{-0.39}$ & Chengdu & 0.90 & 2.29 \\
CP & $L P_{i}=2458.24 R_{i}^{-0.40}$ & Zhengzhou & 0.96 & 2.41 \\
HC & $L P_{i}=1716.59 R_{i}^{-0.82}$ & Harbin & 0.87 & 1.06 \\
\hline
\end{tabular}

Given the high degree of the rank-size curve fitness of urban agglomerations, the theoretical land price of the primary city within an urban agglomeration can reflect the overall level of land price to a certain extent. In 2019, the theoretical land price of the primary city in GHM was the highest at $17,086.72$ yuan $/ \mathrm{m}^{2}$, which was approximately 10 times higher than that of the primary city in $\mathrm{HC}$ at $1716.59 \mathrm{yuan} / \mathrm{m}^{2}$. The theoretical land prices of the primary cities of the eight urban agglomerations can be classified into three classes according to their high prices: high, medium, and low. GHM and BTH were in the high class, with theoretical land prices of their primary cities at $>17,000$ yuan $/ \mathrm{m}^{2}$. YRD was in the medium class, with its primary city's theoretical land price at $8638.68 \mathrm{yuan} / \mathrm{m}^{2}$. $\mathrm{BG}, \mathrm{CC}, \mathrm{CP}$, and $\mathrm{HC}$ were in the low class with a theoretical land price of $<4000 \mathrm{yuan} / \mathrm{m}^{2}$.

The slopes of the land price rank-size curves of major urban agglomerations during 2007-2019 are shown in Table 5. Temporally, only CC showed a decreasing Zipf and increasing $\mathrm{D}$, indicating that the changes in the distribution of land prices of its cities tend to be balanced, and the gap between the land prices of cities in high and low ranks gradually narrowed. The remaining seven urban agglomerations showed a trend of increasing Zipf and decreasing $\mathrm{D}$, suggesting imbalance within urban agglomerations, and a gradual increase in the differences between high- and low-ranking cities. Among these seven urban agglomerations, the slope of the change in Zipf was the largest in BTH, reflecting that the rank-size distribution of its land prices tended to be the most uneven, followed by GHM, BG, HC, YRD, MRY, and CP. Furthermore, the rank-size distributions of land prices within the urban agglomerations tended to be less uneven in that order. In terms of the theoretical land price of the primary city, BTH had the highest average annual increase of 1724.846 yuan $/ \mathrm{m}^{2}$, which was more than 17 times higher than that of the lowest in HC at 96.638 yuan $/ \mathrm{m}^{2}$. The relationship between the slopes of the theoretical land price of the primary city in the urban agglomeration was consistent with the theoretical land price, resulting in a widening gap between the land prices. 
Table 5. Slopes of the parameters of the rank-size model for the land price of major urban agglomerations during 2007-2019.

\begin{tabular}{cccc}
\hline Urban Agglomeration & $\mathbf{q}$ & $\mathbf{D}$ & $\mathbf{T L} \boldsymbol{P}_{\boldsymbol{i}, 1}$ \\
\hline BTH & 0.168 & -0.083 & 1724.846 \\
GHM & 0.063 & -0.063 & 1686.245 \\
BG & 0.055 & -0.083 & 342.308 \\
HC & 0.031 & -0.069 & 96.638 \\
YRD & 0.024 & -0.059 & 765.020 \\
MRY & 0.022 & -0.079 & 309.772 \\
CP & 0.007 & -0.036 & 168.481 \\
CC & -0.006 & 0.019 & 194.159 \\
\hline
\end{tabular}

\section{Discussion}

During 2007-2019, the rank-size distributions of the urban land-price system in China showed double fractal structures; however, the structures changed over time, displaying the following characteristics: (1) the tendency of the fitted curve of non-scale area I becomes steeper, (2) the position of the turning point between non-scale areas I and II shifts forward, and (3) the gap between the slopes of the fitted curve of non-scale areas I and II becomes narrower. The mechanisms of these characteristics are discussed below.

Slope steepening of non-scale area I is caused by the land prices in high-ranking cities rising faster than those in low-ranking cities because of the increase in land prices in China's cities during the entire study period. This phenomenon has two aspects: acceleration and deceleration of the slope of land price in high-ranking (Figure 7a) and low-ranking cities (Figure $7 \mathrm{~b}$ ), respectively. The slopes of the average land prices of the high-ranking (1-30) and low-ranking (201-230) cities in non-scale area I were further calculated to determine the reasons for the steepening of slope of non-scale area I.

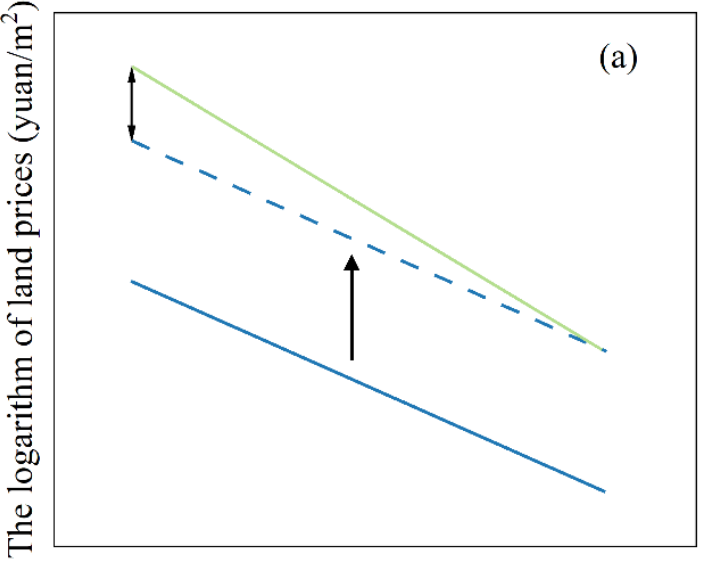

The logarithm of land price rank

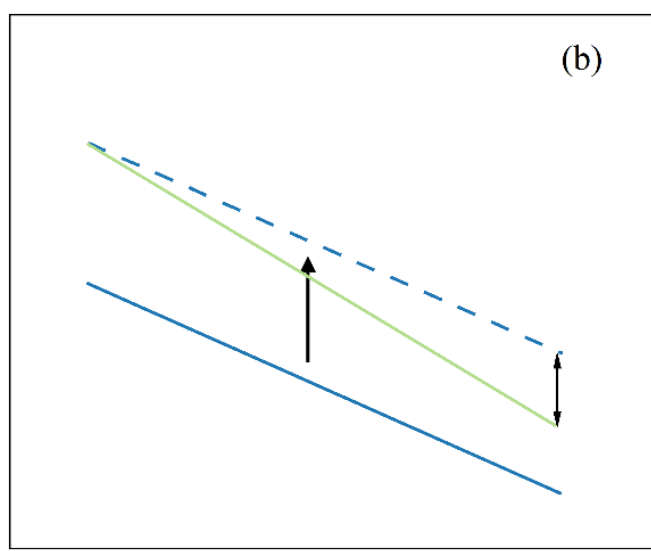

The logarithm of land price rank

Rank-size log curve of original land price

- - - Rank-size log curve of land price when land price growth rate is the same in high-ranking and low-ranking cities Rank-size log curve of actual land price

Figure 7. The steepness of the slope of land price in high-ranking cities is higher than that in lowranking cities. (a) Accelerated growth scenario in high-ranking cities; (b) slower growth scenario in low-ranking cities.

Results show that the slopes of average land prices in both the high-ranking cities and the low-ranking cities displayed an upward trend, with the increase rate of the average land price in the high-ranking cities being significantly higher than that in the low-ranking cities (Figure 8a). Therefore, we can conclude that the steepening of the slope of non-scale area I was due to the acceleration of land prices in the high-ranking cities. 

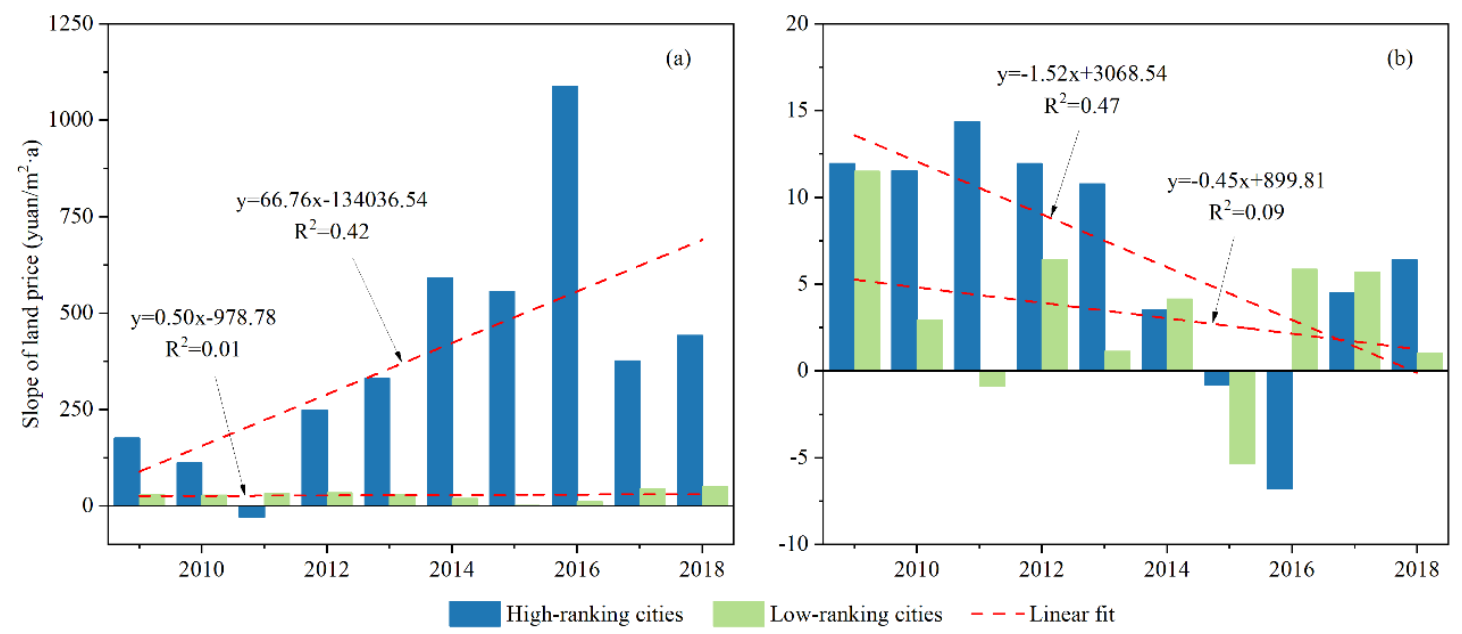

Figure 8. Changes in the average slopes of land prices of high-ranking and low-ranking cities in (a) non-scale area I and (b) non-scale area II. To minimize fluctuations, the slopes of land price are expressed as the three-year average of the slopes in the previous, current, and the following years.

The above phenomenon reflects the unbalanced development between high-ranking and low-ranking cities because of the difference in the slopes of land prices. This phenomenon can be explained by the uneven regional economic growth theory [48]. In the process of development, industries, capital, and labor are always concentrated in cities where economic activities occur. This concentration, in turn, makes these regions more attractive to more industries, capital, and labor, thus causing a positive feedback mechanism in which the developed regions become more and more capital intensive, while backward regions find it difficult to develop [49,50], which is reflected spatially in the "siphoning effect". As a result of this combined growth, high-ranking cities have the potential to accelerate their development momentums compared to low-ranking cities, thereby causing additional migration and concentration of industries, capital, and labor, and thus increasing the demand for land, causing uneven growth. Contrarily, the steepening of the slope of the fitted curve in non-scale area I is also consistent with the direction of change in the land rent curve. With social development, population migration, and technological innovation, high-quality resources are concentrated in high-ranking cities, thereby causing a marginal increase in the intensive capacity of these cities, while low-ranking cities develop slowly. This effect is reflected in land prices, which rise faster in high-ranking cities compared to low-ranking cities.

During 2007-2019, the position of the turning point between non-scale areas I and II moved from the 280th to 239th rank. This implies that despite new cities moving into nonscale area I, at least 41 cities kept pace with the development of China's urban development system and were left out of the system during the 13-year development process. For these reasons, there is a correlation between the forward shift of the turning point and the steepening of the slope of the fitted curve in non-scale area I, which is similar to the process of land marginalization that influences the polarization of high-ranking cities in the development process. As a result, the demand in the land market did not increase or decrease sharply, which eventually caused the rate of increase in land price increase to be disconnected from that of the cities in the high-ranking cities, thus causing marginalization. In fact, during the study period, 17 cities moved into non-scale area I and participated in China's urban development system; that is, 58 cities underwent "marginalization" spatially (Figure 9). Cities that moved out of non-scale area I were mainly concentrated in the northwestern region and around major urban agglomerations, while cities that moved into non-scale area I had no obvious spatial distribution pattern. 


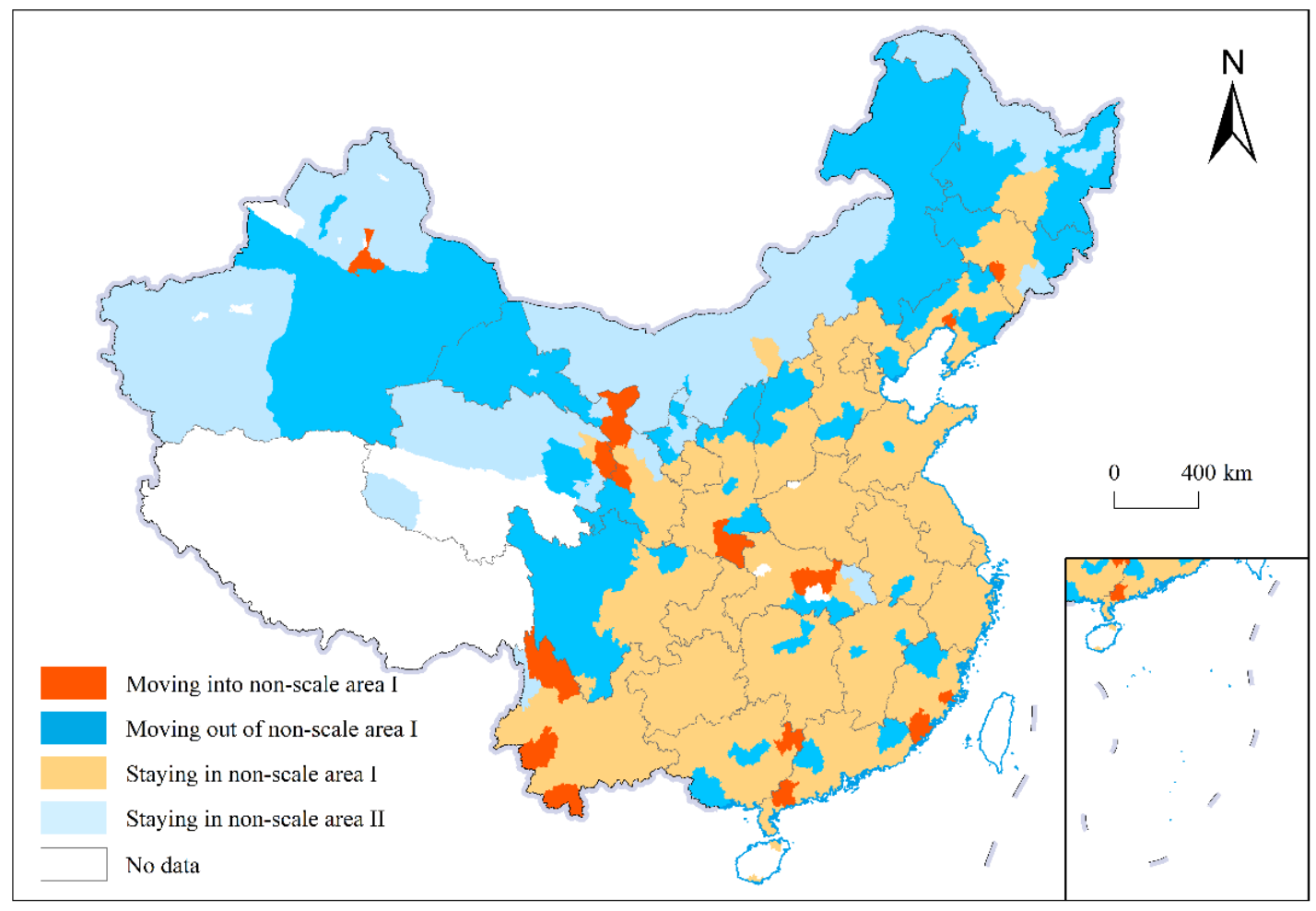

Figure 9. Spatial distribution of cities moving into and out of non-scale area I during 2007-2019.

It is easy to notice that most of the cities that moved out of non-scale area I are resource-based cities. On the one hand, the development of tertiary industries in these cities was low, their resources tended to gradually be depleted, and their economic growth momentum continued to weaken with long-term resource exploitation. On the other hand, the granting of more industrial land concessions in resource-based cities had lowered the average land price, thus resulting in difficulties in maintaining the increase of land prices in these cities in line with the overall development of non-scale area I causing them to move out. For further verification, the slopes of GDP and permanent population in the four types such as "moving into non-scale area I", "moving out of non-scale area I", "staying in non-scale area I", and "staying in non-scale area II" were analyzed, as shown in Figure 10. Economically, the GDP slope was 3.209 billion yuan/year in cities that moved from non-scale area I into non-scale area II, which was much lower than that of cities in non-scale area I (13.212 billion yuan/year) and even lower than that of cities that moved into non-scale area I. However, the slope of the GDP of cities that moved into non-scale area I (5.820 billion yuan/year) was higher than that of those cities that had remained in non-scale area II (2.342 billion yuan/year). The slope of the permanent population of the four types of cities was similar to that of the slope of the GDP; however, for the cities that moved out of non-scale area I, it decreased at an average annual rate of 0.04 million people. In contrast, the slope of the population of cities moving into non-scale area I was only 0.08 million/year higher than that of cities that remained in non-scale area II. The economic and population changes of the four types of cities explain the changes in cities in the urban land-price system in China. The cities that stayed in non-scale area II had slow economic and population growth during the development process. The economic growth of the cities that had moved out of non-scale area I was much lower than its average level. The populations also experienced negative growth, making it difficult for them to keep up with the pace of the urban development system in the process of development and, hence, they had stagnated. The slope of the economy and population of the city that moved into non-scale area I from non-scale area II was higher than the average levels of those that remained in non-scale area II. This is especially the case for economic development, which 
stood out in non-scale area II, and then, with the increase in urban land price, it entered the urban development system.

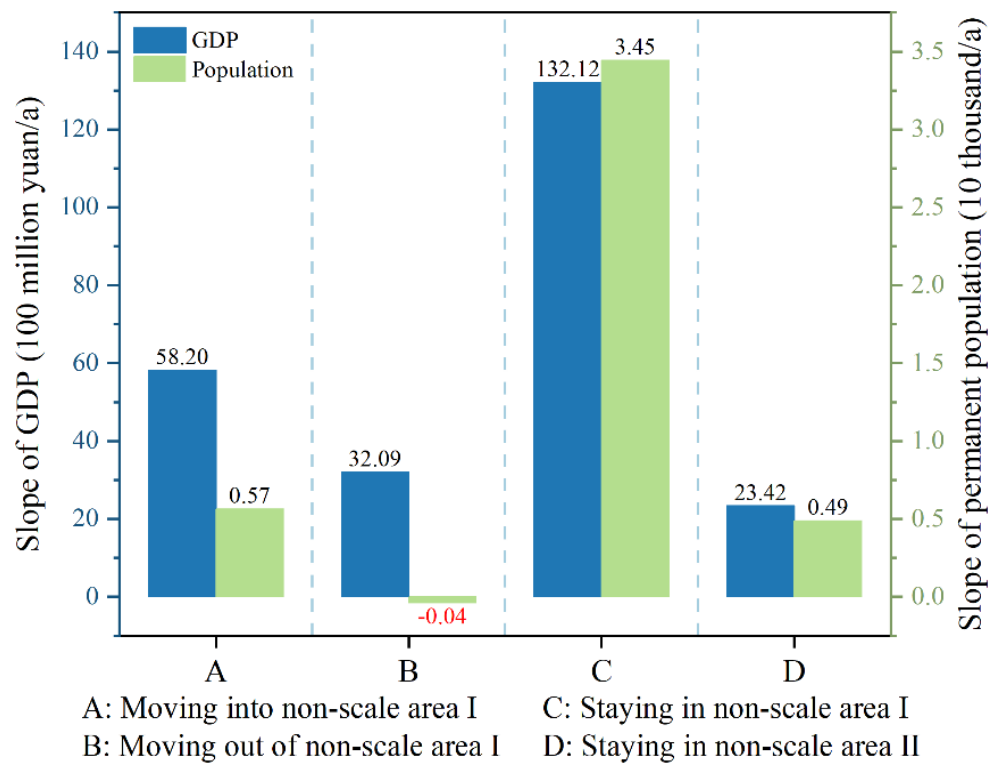

Figure 10. Slopes of GDP and resident population in four types of cities during 2007-2019.

The difference in the slope of the fitted curve between non-scale area II and non-scale area I decreased during the study period, reflecting the decreasing trend of the difference in the equilibrium of land prices between cities within and outside the urban development system. This phenomenon was due to the significant increase in the slope of the fitted curve of non-scale area II, which tended to level off. The above method was used to determine whether the slowdown in non-scale area II was due to a slowdown in the slope of land prices in the high-ranking cities or an acceleration in the slope of land prices in the lowranking cities; the changes in the slope of land prices in the high-ranking (281-290) and low-ranking (311-320) cities in non-scale area II were analyzed separately. Results showed (Figure $8 b$ ) that the slope of land price in both high- and low-ranking cities in non-scale area II showed a decreasing trend, while the slope of land prices in high-ranking cities decreased faster, so that the slope of non-scale area II slopes down from the slowdown of the rise of land prices in the high-ranking cities. This result was exactly the opposite of that for non-scale area I, indicating that although the slope of land prices of high-ranking cities in non-scale area II was higher than that of low-ranking cities during the study period, the difference between the slope of land prices of high-ranking and low-ranking cities tends to decrease, which will eventually lead to the land prices of low-ranking cities catching up with those of high-ranking cities, and the gap between them will narrow. Therefore, the land price distribution of cities in non-scale area II gradually tended to be balanced in the development process. This is probably because the high-ranking cities in non-scale area II were also affected by the polarization effect of the high-ranking cities in non-scale area $\mathrm{I}$, resulting in an outflow of population and industries from the cities and the continuous weakening of land demand, which caused the slowdown of the rise of land prices. The lower-ranking cities in non-scale area II were less influenced by macro factors because of their lower development levels, lesser local industries, and lower population mobility.

The trend of land prices in the high- and low-ranking cities in non-scale areas I and II reflected the widening gap between them, indicating that there was a constant impetus for land prices to rise in the high-ranking cities at the national scale, while the development capacity of the low-ranking cities was limited. Under these circumstances, without intervention, urban land prices in China will tend to polarize. 


\section{Conclusions}

This study analyzed the rank-size distribution and fractal feature characteristics of the urban land-price system in China and eight major urban agglomerations based on land transfer data during 2007-2019. The main conclusions are as follows:

(1) From 2007-2019, the average urban land price in China showed a significant upward trend with an average growth rate of $80.73 \mathrm{yuan} /\left(\mathrm{m}^{2} \cdot \mathrm{a}\right)$. It also shows a spatial clustering distribution.

(2) The rank-size law describes the distribution of the urban land-price system in China. The rank-size distribution of land prices is balanced with more low-ranking cities and less high-ranking cities. The degree of equilibrium of the land-price system changed, showing a "balanced-unbalanced" development trend in general. The $r$ of cities was low in the southeast and high in the northwest, with low values concentrated in the eastern region, especially in urban agglomerations. High values were concentrated in the northwest region, mostly in small and medium-sized low-ranking cities, indicating that the cities in northwest China still have more development space.

(3) Double fractal structures of China's land price rank-size distribution were found during 2007-2019. During the study period, these fractal structures showed a steep slope of the fitted curve for non-scale area I; the position of the turning point between non-scale areas I and II shifted forward, and the gap between slopes of the fitted curve of non-scale areas I and II reduced. This is mainly related to the uneven growth of urban land prices. The polarization effect leads to the concentration of industries, capital, and labor in cities in the high order of development, which continuously increases the demand for land and causes land prices to rise, and the rise in land prices will further attract the concentration of population and capital. The outflow of population and industry from cities in the lower order causes a decrease in the growth rate of land demand in these cities. In addition, the lower-ranked cities have little change in land prices because of their lower level of development.

(4) Among the eight urban agglomerations, there was a large gap in land prices between high-ranking and low-ranking cities in BTH and GHM. In contrast, the land prices of high-ranking and low-ranking cities were balanced in CC and CP. There is still a large difference between urban agglomeration land-price systems and this difference tends to continue to grow, reflecting the widening gap in development levels between urban agglomerations in China.

This study applies the rank-size law and fractal theory to urban land prices, which is a new attempt and would provide a new idea for the study to apply the rank-size law to other attributes of cities. In addition, the shortcoming of this study is that the land prices of different land types transferred by agreement, tender, auction, and listing are considered together, which can reflect the comprehensive development status of the city but are more general. The proportions of the area of the different ways of transferring and different land types would affect the urban land price, which may generate deviation on the results from the real situation.

Based on the above results, we suggest that the small and medium-sized cities in China still have considerable space for development, which can be improved by categorically guiding the development direction and construction priorities, and coordinating and guiding the layout of the industries and capital of these cities. Besides, the strategy of strengthening the linkage mechanisms within and between urban agglomerations should be considered to improve multi-level coordination mechanisms and cost-sharing benefitsharing mechanisms in urban agglomerations, and to give full play to the radiation-driven role of high-ranked cities in urban agglomerations with lower equilibrium, especially those with large internal land price differences (such as BTH and GHM). Moreover, ensuring synergistic development of industries between urban agglomerations is also critical. To strengthen the cooperation and exchanges of various industries between eastern coastal urban agglomerations and northern, central, and western urban agglomerations, would 
thus realize the complementary advantages and divisions of labor between urban agglomerations to reduce the development gap between the east and west of China.

Author Contributions: Conceptualization, X.L.; methodology, X.L.; software, X.L.; validation, X.L.; formal analysis, X.L.; writing—original draft preparation, X.L.; writing—review and editing, L.X.; visualization, X.L.; supervision, L.X.; funding acquisition, L.X. All authors have read and agreed to the published version of the manuscript.

Funding: This research was funded by the National Natural Science Foundation of China, grant number 42171259 .

Data Availability Statement: The land transfer data presented in this study are openly available in China Land Market Network (http:/ / www.landchina.com, accessed on 18 January 2022).

Conflicts of Interest: The authors declare no conflict of interest.

\section{References}

1. Zeng, G.; Ma, Y. A study on the impact of land price on urban industrial structure upgrading: An empirical analysis based on urban data of 105 prefecture-level and above prefecture-level cities. Macroeconomics 2019, 95-107.

2. Yan, X.; Zhang, P. Land price, land finance, and macroeconomic fluctuations. J. Financ. Res. 2019, 471, 1-18.

3. Yang, S.; Hu, S.; Qu, S. Spatial analysis of the relationship between urban land price and urbanization rate: An empirical study of 80 counties in Hubei. Resour. Sci. 2017, 39, 325-334.

4. Deng, X.; Liang, L.; Wu, F.; Wang, Z.; He, S. Chinese balanced regional development strategy from the perspective of development geography. Acta Geogr. Sin. 2021, 76, 261-276.

5. Chai, Z.; Zhao, S.; Li, Z.; Wu, L. Empirical analysis on relationship between land price and economic growth: A case of eastern region. China Land Sci. 2009, 23, 9-13.

6. Perroux, F. Economic space: Theory and applications. Q. J. Econ. 1950, 64, 89-104. [CrossRef]

7. Yuan, S.; Zhu, C.; Yang, L. Spatial Analysis of Various Land Price and Its Influencing Factors in Yangtze River Delta Agglomeration. Resour. Environ. Yangtze Basin 2017, 26, 1538-1546.

8. Zhao, S.; Tian, Y.; Zhou, G.; Wu, R.; Chai, Z. Study on the Urban Land Price of Various Land Uses. China Land Sci. 2011, 25, 4-9.

9. Zhou, P.; Zeng, Z. Study on Relationship Between Urbanization and Urban Land Price-Panel Data Analysis from 31 Provinces in China. Resour. Dev. Mark. 2013, 29, 44-47+63.

10. Zhang, H.; Jin, J. Spatial Variation of Urban Land Price in China: A Case Study of Kunming. China Land Sci. 2007, 24-30.

11. Song, J.; Jin, X.; Tang, J.; Zhang, Z.; Ding, N.; Zhou, Y. Analysis of Influencing Factors for Urban Land Price and Its Changing Trend in China in Recent Years. Acta Geogr. Sin. 2011, 66, 1045-1054.

12. Wang, Y.; Wang, D.; Liu, L.; Yan, M.; Wang, S. Spatial Differentiation of Urban Housing Prices and Its Impacts on Land Market in China. China Land Sci. 2015, 29, 33-40.

13. Zhang, L.; Yang, H.; Ge, J.; Liang, Y. Research on Land Price Gravity Movement and Its Driving Factors of Major Cities in China. Geogr. Geo-Inf. Sci. 2014, 30, 70-74.

14. Kaldor, N. Causes of the Slow Rate of Economic Growth of the United Kingdom: An Inaugural Lecture; Cambridge UP: London, UK, 1966.

15. Thirlwall, A.P. Growth And Development: With Special Reference To Developing: With Special Reference to Developing Economies; Macmillan International Higher Education: Basingstoke, UK, 1994.

16. Fujita, M.; Thisse, J.-F. Economics of agglomeration. J. Jpn. Int. Econ. 1996, 10, 339-378. [CrossRef]

17. Krugman, P. Increasing returns and economic geography. J. Political Econ. 1991, 99, 483-499. [CrossRef]

18. Moran, P.A. The interpretation of statistical maps. J. R. Stat. Society. Ser. B (Methodol.) 1948, 10, 243-251. [CrossRef]

19. Anselin, L. Spatial Econometrics: Methods and Models; Springer Science \& Business Media: Berlin, Germany, 1988; Volume 4.

20. Wang, S.; Wang, Y.; Lin, X.; Zhang, H. Spatial differentiation patterns and influencing mechanism of housing prices in China: Based on data of 2872 counties. Acta Geogr. Sin. 2016, 71, 1329-1342.

21. Mo, Y.; Liu, Y.; Zhu, L. Spatial Differentiation Patterns and Influencing Factors of Urban Land Prices in Yangtze River Economic Belt. Resour. Environ. Yangtze Basin 2020, 29, 13-22.

22. Yang, K. Research on Tempo-Spatial Characteristics of Urban Land Value in China from the Perspective of Urban Systems; China University of Mining and Technology: Xuzhou, China, 2014.

23. Wasserman, S.; Faust, K. Social Network Analysis: Methods and Applications; Cambridge University Press: Cambridge, UK, 1994.

24. Taylor, P.J. Specification of the world city network. Geogr. Anal. 2001, 33, 181-194. [CrossRef]

25. Herbert, D.T.; Thomas, C.J. Urban Geography: A First Approach; Wiley: Hoboken, NJ, USA, 1982.

26. Jiang, H.; Cai, S.; Li, B. The rank-size distribution of civil airport system and its mechanism in the Yangtze River Delta. Sci. Geogr. Sin. 2021, 41, 615-624.

27. Guo, J.; He, Y.; Wang, S.; Wu, L. Rank-size distribution changes and transportation network connections of the coastal container port system in Chinese mainland since 1985. Geogr. Res. 2019, 38, 869-883. 
28. Li, T.; Cao, X.; Yang, W. Rank-size distribution and evolution of passenger and freight flows in the Pearl River Delta. Prog. Geogr. 2016, 35, 108-117.

29. Xu, Q.; Huang, T.; Chen, J.; Wan, Z.; Qin, Q.; Song, L. Port rank-size rule evolution: Case study of Chinese coastal ports. Ocean Coast. Manag. 2021, 211, 105803. [CrossRef]

30. Liu, L.; Chen, J. Difference and influncing factors of inboound tourism scale: Evidence from the key provinces in China along the Belt and Road. Econ. Geogr. 2020, 40, 191-201.

31. Yang, X.; Peng, F.; Zhang, Q.; Hu, W. The rank-size distribution and influencing factors of foreign trade in China's border from 2000 to 2017. World Reg. Stud. 2020, 29, 1102-1112.

32. Zhu, H.; Sun, G. Has the domestic tourism of Hubei province been distributed balancedly: An analysis by applying the rank-size rule to high priority regions. J. Zhejiang Univ. (Sci. Ed. ) 2020, 47, 244-252.

33. Wang, Y.; Zhu, M.; Zhao, Y. Scale system and dynamic change characteristics of natural gas flow in China. World Reg. Stud. 2019, 28, 153-164.

34. Zhao, Y.; Niu, H.; Yang, Z. Study on the rank-size distribution and variation of crude oil flow in China. Geogr. Res. 2010, 29, 2121-2131

35. Auerbach, F. Das gesetz der bevölkerungskonzentration. Petermanns Geogr. Mitt. 1913, 59, 74-76.

36. Singer, H.W. The" courbe des populations." A parallel to Pareto's Law. Econ. J. 1936, 46, 254-263. [CrossRef]

37. Grachev, G.A. Size Distribution of States, Counties, and Cities in the USA: New Inequality Form Information. Phys. A: Stat. Mech. Its Appl. 2020, 592, 126831. [CrossRef]

38. Kundak, S.; Dökmeci, V. A rank-size rule analysis of the city system at the country and province level in Turkey. ICONARP Int. J. Archit. Plan. 2018, 6, 77-98. [CrossRef]

39. Taubenböck, H.; Weigand, M.; Esch, T.; Staab, J.; Wurm, M.; Mast, J.; Dech, S. A new ranking of the world's largest cities-Do administrative units obscure morphological realities? Remote Sens. Environ. 2019, 232, 111353. [CrossRef]

40. Yu, T.; Liu, Y.; Zhu, L.; Hu, Z.; Mo, Y. Coupling Analysis of Spatial Features of Urban Land Price and Nighttime Light Intensity in China. Territ. Nat. Resour. Study 2021, 5, 57-64.

41. Luo, J.; Zhang, X.; Wu, Y.; Shen, J.; Shen, L.; Xing, X. Urban land expansion and the floating population in China: For production or for living? Cities 2018, 74, 219-228. [CrossRef]

42. Liu, Z.; Wang, P.; Zha, T. Land-price dynamics and macroeconomic fluctuations. Econometrica 2013, 81, 1147-1184.

43. Du, X.; Huang, Z.; Wu, C. Land finance and economic growth in China-An analysis based on Inter-Provincial panel data. Financ. Trade Econ. 2009, 60-64.

44. Zhao, A.; Lan, J.; Ma, X.; Xu, S. The impact of land price marketization on factor input and technology choice in China's industrial sector. J. Financ. Econ. 2016, 42, 85-96.

45. Chen, Y. Monofractal, multifractals, and self-affine fractals in urban studies. Prog. Geogr. 2019, 38, 38-49.

46. Wu, Z.; Dai, X.; Yang, W. On reconstruction of parato formula and its relationship with development of urban system. Hum. Geogr. 2000, 15-19.

47. National Bureau of Statistics, C. 2017 Zoning Codes and Urban-Rural Division Codes for Statistics. Available online: http: //www.stats.gov.cn/tjsj/tjbz/tjyqhdmhcxhfdm/2017/index.html (accessed on 19 January 2022).

48. Hirschman, A. The Strategy of Economic Development; Yale University Press: London, UK, 1958.

49. Liu, A.; Ma, R.; Wang, M.; Yang, K. A new economic geography explanation for urban and regional development differences in China-An empirical study based on the variable payoffs of scale hypothesis. Inq. Into Econ. Issues 2016, 88-96.

50. Liu, A.; Li, Q. A research of progressive rewark increase, path dependence and endogenous regional growth difference. Econ. Surv. 2007, 60-63. 